\title{
Non-invasive assessment of adrenocortical function as a measure of stress in the endangered golden langur
}

\author{
Jatin Sarmah ${ }^{1}$, Chaya R. Hazarika ${ }^{2}$, Elizabeth V. Berkeley ${ }^{3, *}$, Stefanie Ganswindt ${ }^{4}$ \\ and Andre Ganswindt ${ }^{5}$
}

\author{
${ }^{1}$ Bodoland University, Kokrajhar, Assam \\ ${ }^{2}$ Department of Anthropology, Gauhati University, Kokrajhar, Assam \\ ${ }^{3}$ Biology and Earth Science, Otterbein University School of Arts and Sciences, Westerville, Ohio \\ ${ }^{4}$ Anatomy and Physiology, University of Pretoria Faculty of Natural and Agricultural Sciences, ZA, Pretoria, \\ South Africa \\ ${ }^{5}$ Department of Animal Reproduction Sciences, University of Pretoria, Pretoria, South Africa
}

\begin{abstract}
*Correspondence
Dr. Elizabeth V. Berkeley, Biology and Earth Science, Otterbein University School of Arts and Sciences, 1 South Grove Street, Westerville, $\mathrm{OH}$.

Email: eberkeley@otterbein.edu
\end{abstract}

\begin{abstract}
The golden langur (Trachypithecus geei) is an endangered primate endemic to northern India and Bhutan. The main stressors to the species are habitat degradation and fragmentation. Non-invasive fecal glucocorticoid metabolite (fGCM) analysis is a powerful tool for assessing stress associated with environmental disturbances in wildlife. However, interspecific differences in glucocorticoid metabolism require careful selection of the antibody used in their quantification. The goals of this study were to: 1) validate an enzyme immunoassay (EIA) to determine fecal GC metabolite (fGCM) concentrations in the golden langur and 2) compare fGCM concentrations between golden langurs living under different environmental conditions. We compared five enzyme immunoassays for determining stress related physiological responses in golden langurs by performing an adrenocorticotropic stimulation test in both sexes. Our validations identified an 11-oxoaetiocholanolone EIA detecting 11, 17 dioxoandrostanes as the most suitable assay for monitoring adrenocortical activity in the species. FGCM concentrations from semi-captive temple langurs were significantly higher than respective stress steroid concentrations in free-ranging or pet/zoo langurs. This study presents a validated practical method for non-invasive monitoring of adrenocortical function in this rare and declining species.
\end{abstract}

Keywords: ACTH challenge test; enzyme immunoassay; fecal glucocorticoid metabolites; golden langur; non-invasive stress monitoring 


\section{INTRODUCTION}

The golden langur (Trachypithecus geei) is an endangered Cercopithecine primate species [Das et al, 2008]. The species was first identified by biologists in the mid-20 $0^{\text {th }}$ century [Khajuria, 1955], but little research has been performed since that time. The golden langurs are endemic to hilly terrain in Bhutan (T. g. bhutanensis) and in the Assam region of northeastern India (T. g. geei) [Horwich et al., 2013; Wangchuk, 2003]. Approximately 4000 individuals currently occur in Bhutan and another 1500 in India, with a small number held in captivity as pets and in several zoos in India. One small isolated population of the Indian golden langurs, located on the island of Umananda in the Brahmaputra river just off the coast of Guwahati, is culturally significant as they live in a Hindu temple dedicated to Shiva [Mehdi et al., 2007]. The overall population is described as declining, with more than $30 \%$ lost over the past 40 years [Molur et al., 2003]. The main threats to their persistence include habitat degradation and fragmentation [Horwich et al., 2013] but how the population is responding to these threats is not known.

We can assess the ability of individuals to cope with environmental challenges such as habitat degradation, food availability and climate change by measuring physiological stress [Wikelski and Cooke, 2006]. Stress, associated with prolonged periods of elevated glucocorticoid (GC) concentrations, can interfere with numerous physiological processes critical to individual health and survival, including immune and reproductive function and disease resistance [Wingfield and Sapolsky, 2000]. Different studies on captive and free-ranging primates have shown that chronic stress has many negative effects in both males and females. It may suppress libido, spermatogenesis and androgen secretion in males [Norman, 1993; Sapolsky, 1987], while in females its effects are seen in altering ovarian function, embryonic development and infant survival [Bahr et al., 1998]. Some other generalized disruptions of physiological and physical status like hypertension, immune deficiency and increased disease susceptibility have also been observed [Breazile, 1987].

In vertebrates, administration of adrenocorticotropic hormone (ACTH) mimics a natural adrenal stress response by causing a rapid rise in circulating glucocorticoids, followed by a return to baseline level within few hours [Norris, 1996]. A similar pattern occurs in feces, with the onset of the peak excretion delayed by species-specific lag time [Palme et al., 1998]. If the predicted peaks in hormone excretion are detected, the products measured in the feces likely reflect biologically meaningful adrenocortical activity.

Plasma glucocorticoid measurement has been used frequently as a marker for stress in animals, including primates [Johnson et al, 1996]. However, in free ranging and group living animals, capture and restraint is often logistically challenging. Moreover, repeated capture and collection of blood is usually perceived as a stressor itself, and thus potentially exacerbates the stress level determined [Sapolsky and Share, 1998]. Nowadays, we can monitor physiological stress without adding further stress to the animals 
due trapping or handling by measuring glucocorticoid metabolites in alternative matrices such as feces. Species-specific differences in steroid metabolism and gut microflora cause these metabolites to differ among species [Touma and Palme, 2005]. Therefore, to ensure biologically meaningful results from fecal glucocorticoid metabolite (fGCM) analysis, physiological, immunological and biological validations become important [Heistermann et al, 2006].

However, once established, non-invasive monitoring of GC metabolite concentrations offers a viable and advantageous alternative for assessing stress levels in both free-ranging and captive primates [Bahr et al., 2000]. Thus, determination of GC metabolite concentrations in feces have been established as an index of stress in a number of primates [Monfort et al., 1998], including chimpanzees [Thompson, 2013], orangutans [Muehlenbein et al., 2012], brown spider monkeys [Rimbach et al., 2013], lesser bushbabies [Scheun et al., 2015], and lemurs [Fichtel et al., 2007].

The overall aim of this study was to examine the suitability of five different enzyme immunoassays for monitoring adrenocortical function in golden langurs. Our specific objectives were to: 1) validate an enzyme immunoassay to measure fGCM in golden langurs by performing an adrenocorticotropin challenge test, and (2) compare fGCM concentrations from golden langurs living in wild, temple-housed, and captive conditions.

\section{MATERIALS/METHODS}

\section{Study area and animals}

Groups of golden langurs were selected from three different types of living conditions in the region of Assam: free ranging, semi-captive and captive. The free-ranging individuals included adult males $(n=3)$ and females ( $n=2)$, sub-adults ( 1 male and 3 females) and infants ( 1 male and 2 females), belonging to a free-ranging population $(n=501)$ living in the 4557 ha Chakrasila Wildlife sanctuary (CWS), Kokrajhar. This sanctuary was selected as there is thus far no land fragmentation, a known threat to golden langur survival. The semi-captive animals (two adult females and five adult males) lived on a 4.9 hectare riverine island in Guwahati, where a famous Hindu temple is located. The captive animals sampled in this study were housed either at the Assam State Zoo cum Botanical Garden, Guwahati (three males of approximately 10 years of age) or at private households in Kokrajhar (one 5-year old male pet and one 4-year old female pet, used for the ACTH challenge). Dietary information, including types of foods observed eaten by all three groups, is included in the supplementary material online.

The study occurred in winter (December 2014-January 2015) with average maximum and minimum temperatures of $18^{\circ} \mathrm{C}$ and $9^{\circ} \mathrm{C}$ respectively, and no rain. The research complied with protocols approved by the animal ethical committee of Bodoland University and adhered to the legal requirements of India. 


\section{ACTH Challenge Test}

For the ACTH challenge, the five year old male and four year old female pet golden langurs were used. ACTH (corticotropin carboxymethylcellulose injection; Ferring Pharmaceuticals, Ahmadabad, India) was administered IM (6 IU/kg body weight). Fecal samples were collected once a day in the morning (between 0700-0800 a.m.) just prior to injection up to 6 days post injection.

\section{Fecal Sample Collection and Processing}

Fecal samples were collected in plastic bags within 10 minutes of morning defecation from all free-ranging, temple and captive subjects. All samples were stored at $-20^{\circ} \mathrm{C}$ within 30 minutes of collection.

Frozen fecal matter was lyophilized, pulverized, and sieved for removal of seeds or any undigested materials. Steroid hormones were extracted by adding $3 \mathrm{ml} 80 \%$ ethanol to $0.10 \mathrm{~g}$ of fecal powder. The suspension was vortexed for $15 \mathrm{~min}$, then centrifuged for $10 \mathrm{~min}$ at $1500 \times \mathrm{G}$ and the supernatant was decanted. $1 \mathrm{ml}$ of the supernatant was oven dried at $60{ }^{\circ} \mathrm{C}$ until complete dryness. After shipment to the Endocrine Research Laboratory, University of Pretoria, South Africa, the extracts were reconstituted by adding $1 \mathrm{ml}$ ethanol (80\%) and glass beads ( $3 \mathrm{~mm}$ diameter). After $5 \mathrm{~min}$ the solution was vortexed for 30 seconds, and subsequently sonicated for $30 \mathrm{~min}$. The reconstituted extracts were stored frozen until use.

\section{fGCM Analysis}

Fecal extracts $(n=12)$ from the two ACTH treated animals were measured for immunoreactive fGCM concentrations using 5 different enzyme-immunoassays: (i) an 11-oxoetiocholanolone I (detecting 11,17 dioxoandrostanes; 11,17-DOA), (ii) an 11-oxoetiocholanalone II (detecting fGCMs with a 5 $\beta$-3 $\alpha$ -

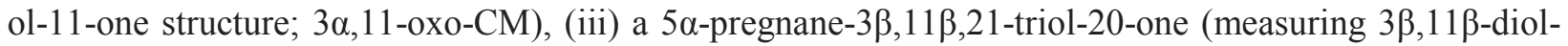
$\mathrm{CM}$ ), iv) a cortisol, and v) a corticosterone EIA. Detailed assay characteristics, including full descriptions of the assay components and cross-reactivities were previously described for 11, 17-DOA, cortisol, and corticosterone [Palme \& Möstl, 1997], for 3a, 11-oxo-CM [Möstl \& Palme 2002], and for the EIA measuring 3 $\beta, 11 \beta$-diol-CMs by Touma et al., [2003].

Subsequently all fecal samples were analyzed with the 11-oxoaetiocholanolone I EIA. In total, there were 96 samples from 12 free-ranging individuals, 11 samples from 7 semi-captive individuals, and 78 samples from 5 captive individuals. The EIA was performed as described previously [Ganswindt et al., 2002]. Sensitivity of the assay was $1.2 \mathrm{ng} / \mathrm{g}$ fecal dry weight. Serial dilutions of fecal extracts gave 
displacement curves parallel to the respective standard curve. Intra-assay coefficients of variation of highand low-value quality controls for the 11 -oxoetiocholanolone I were $5.5 \%$ and $6.2 \%$, respectively, for the 11 -oxoetiocholanalone II assay $6.1 \%$ and $8.7 \%$, respectively, for the $5 \alpha$-pregnane-3 $\beta, 11 \beta, 21$-triol-20one assay $4.9 \%$ and $6.3 \%$, respectively, for the cortisol assay $9.5 \%$ and $11.4 \%$, respectively, and for the corticosterone EIA $4.5 \%$ and $7.9 \%$, respectively. The inter-assay coefficients of variation of high- and low-value quality controls for the 11-oxoaetiocholanolone I assay were $13.0 \%$ and $13.9 \%$, respectively, for the 11-oxoetiocholanalone II assay $12.9 \%$ and $17.3 \%$, respectively, for the $5 \alpha$-pregnane-3 $\beta, 11 \beta, 21$ triol-20-one assay $13.8 \%$ and $17.9 \%$, respectively, for the cortisol assay $12.8 \%$ and $12.9 \%$, respectively, and for the corticosterone EIA $15.5 \%$ and $17.5 \%$, respectively.

\section{Data analyses}

To calculate the EIA specific responses to the ACTH challenge, we set the sample collected from each individual on the day of ACTH administration as $100 \%$ and all other values were expressed as a percentage of the respective value. To compare individual fGCM concentrations in the captive group, individual baseline levels for the two pet animals were calculated using an iterative process as described [Ganswindt et al., 2014]. Differences in fGCM concentrations between individuals and between groups were determined using a Kruskal-Wallis One Way Analysis of Variance on Ranks with a post-hoc pairwise multiple comparison (Dunn's Test) to isolate the individuals or groups that differed from the others in SigmaPlot for Windows versions 12.5.

\section{RESULTS}

\section{ACTH Challenge}

In the female, the 11-oxoaetiocholanolone I assay showed a $700 \%$ increase of fGCM concentrations (from 0.08 to $0.61 \mu \mathrm{g} / \mathrm{g}$ fecal DW) at $48 \mathrm{~h}$ post-ACTH injection. In addition, the $3 \beta, 11 \beta$ diol-CM assay demonstrated a $200 \%$ increase (from 0.38 to $1.17 \mu \mathrm{g} / \mathrm{g}$ fecal DW), and the 11oxoetiocholanalone II a $150 \%$ increase (from 0.67 to $1.66 \mu \mathrm{g} / \mathrm{g}$ fecal DW) two days post-ACTH administration (Figure 1a).

In the male, the cortisol assay performed best, showing an approximate $150 \%$ increase of fGCM concentrations (from 15.6 to $38.2 \mathrm{ng} / \mathrm{g}$ fecal DW), whereas, the group-specific 11-oxoaetiocholanolone I assay demonstrated a $90 \%$ increase (from 0.07 to $0.13 \mu \mathrm{g} / \mathrm{g}$ fecal DW) at $48 \mathrm{~h}$ post-ACTH administration (Figure 1b).

Since only the group-specific EIA 11-oxoaetiocholanolone I assay performed reasonably in both sexes, we selected this assay to analyze the complete sample set. 

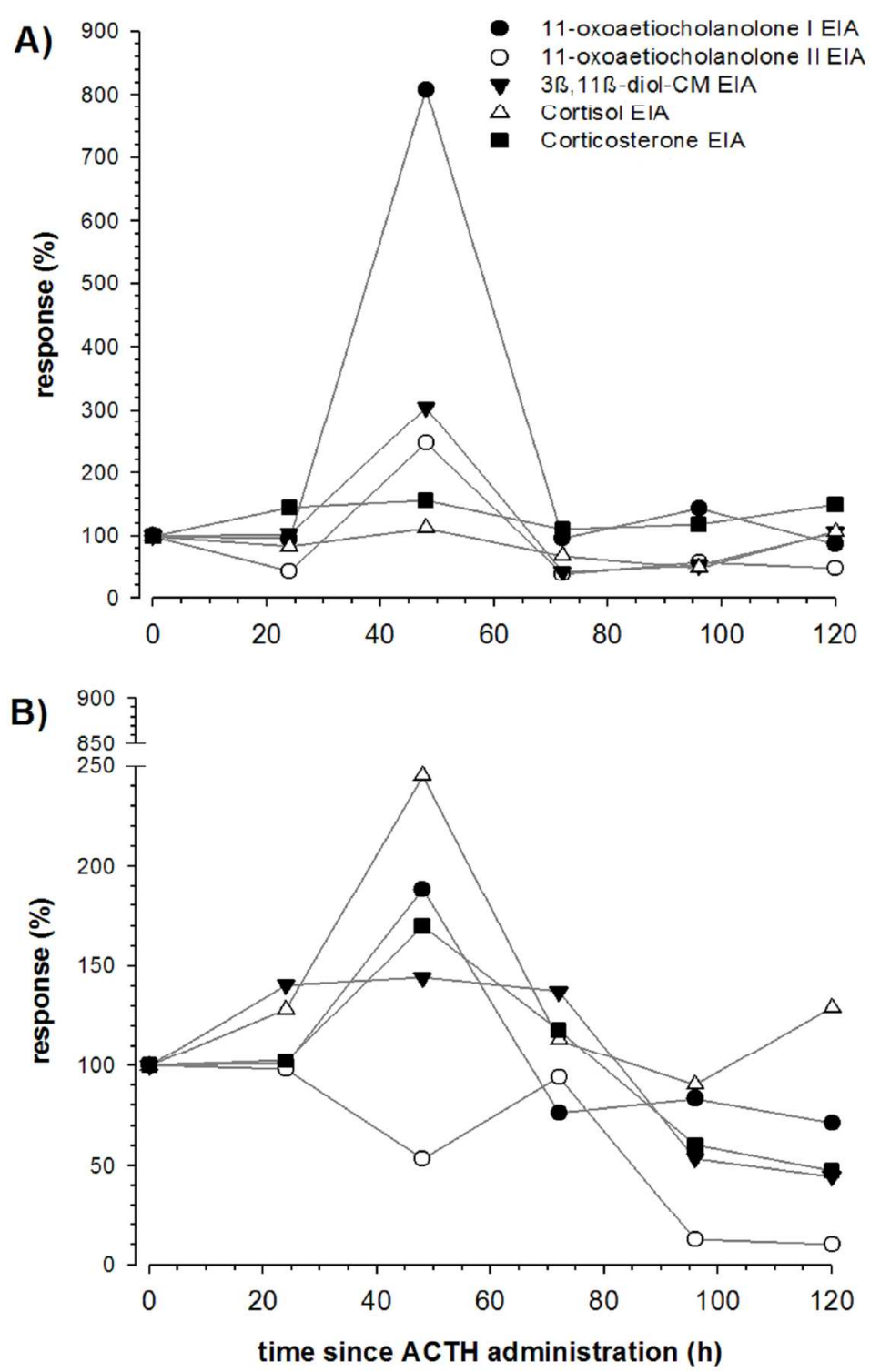

Figure 1. Changes in fecal glucocorticoid metabolite (fGCM) concentrations in response to corticotropin (ACTH) injection in two golden langurs. ACTH was administered at time 0 and fecal samples were collected once every 24 hours over a five day period from A) an adult female, B) an adult male. Changes in fGCM concentrations are expressed as percentages of the respective day 0 fGCM

$264 \times 430 \mathrm{~mm}(144 \times 144 \mathrm{DPI})$ 


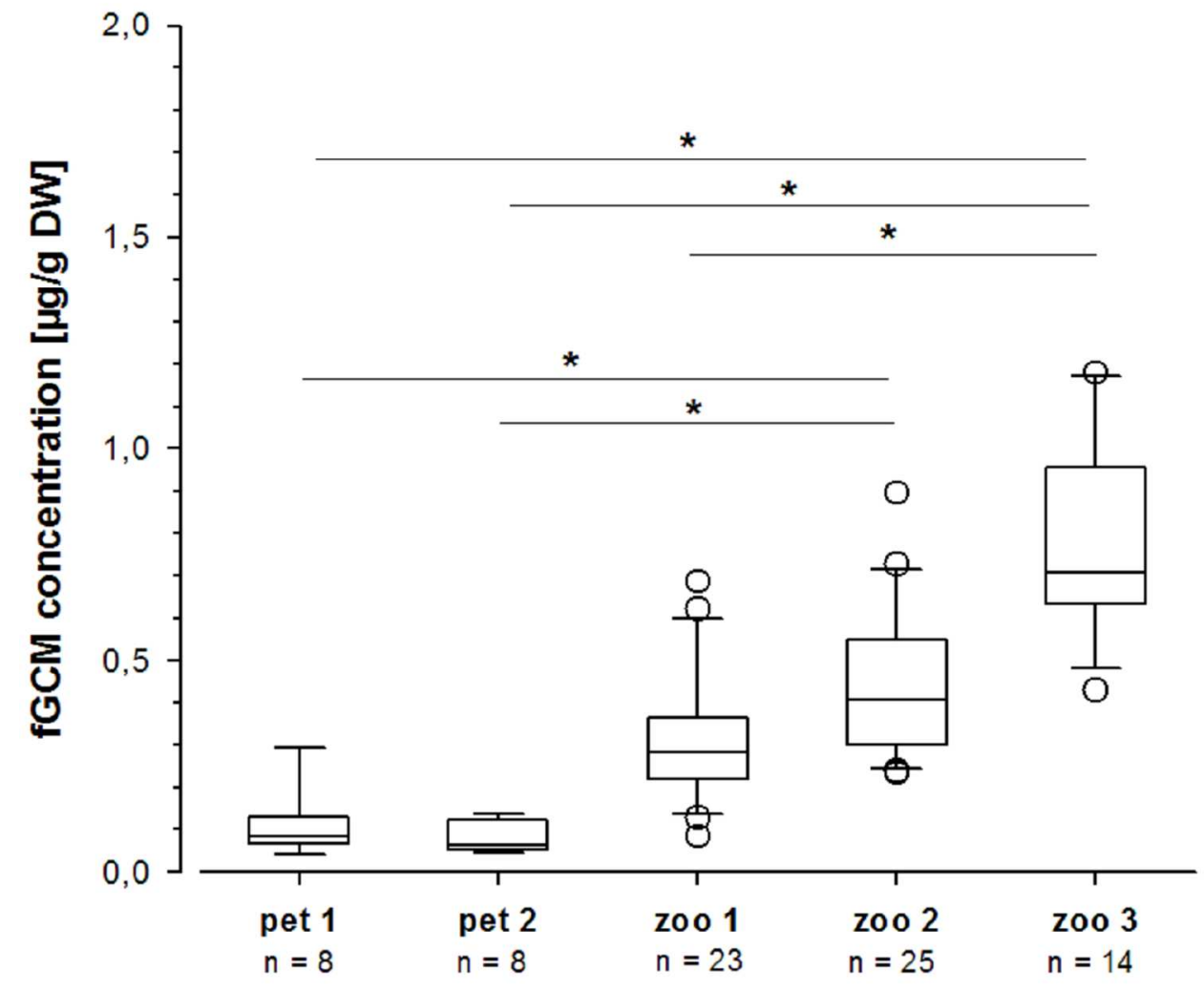

\section{animals}

Figure 2. Box plots of immunoreactive fecal glucocorticoid metabolite (fGCM) concentrations, expressed as micrograms per gram dry weight $(\mu \mathrm{g} / \mathrm{g}$ fecal DW), from individual captive golden langurs, $\mathrm{n}=$ number of fecal samples. Boxes indicate the median and the upper and lower quartile values, whiskers indicate 10th and 90th percentiles of the values, open circles indicate outliers. Horizontal bars and asterisks indicate significant differences between individuals $(P<0.05)$.

$264 \times 246 \mathrm{~mm}(144 \times 144$ DPI $)$ 


\section{Individual fGCM variation in captive animals}

Median fGCM concentrations significantly varied between captive individuals (Kruskal-Wallis One Way Analysis of Variance on Ranks: $\mathrm{H}=52.8, \mathrm{df}=4, \mathrm{P}=0.001$ ) with a range of 0.08 to $0.71 \mu \mathrm{g} / \mathrm{g}$ fecal DW (Figure 2). Golden langur Zoo 3 had the highest fGCM concentrations, with levels up to 1.16 $\mu \mathrm{g} / \mathrm{g}$ fecal DW, and was significantly higher than Pet 1, Pet 2 or Zoo 1 (Dunn's Test: $\mathrm{P}<0.05$ ). The golden langur Zoo 2 also had significantly higher fGCM concentrations than Pet 1 or Pet 2 (Dunn's Test: $\mathrm{P}<0.05)$.

\section{Variation of fGCM under different living conditions}

Median fGCM concentrations varied significantly between the free-ranging, semi-captive, and captive groups (Kruskal-Wallis One Way Analysis of Variance on Ranks: $\mathrm{H}=9.839$, $\mathrm{df}=2, \mathrm{P}=0.007$ ) from a range of 0.32 to $0.85 \mu \mathrm{g} / \mathrm{g}$ fecal DW (Figure 3). The median fGCM concentrations in the temple langurs was significantly higher than either the monitored free-ranging or captive groups (Dunn's Test: $\mathrm{P}<0.05)$.

\section{DISCUSSION}

An ACTH challenge resulted in a 7-fold and 1-fold increase in fGCM concentrations at 48 hours post-administration as assayed by the 11-oxoaetiocholanolone I assay in female and male golden langurs respectively (Figure 1). Despite potential individual or procedural variation, the difference in response points towards a potential sex specific response of glucocorticoid metabolism in golden langurs as has been observed in other species [Touma, et al., 2003].

Due to logistical constraints, we were unable to determine the physiological stress responses individually in the semi-captive and free-ranging golden langur populations and therefore can only present fGCM concentrations on a group level. The 11-oxoaetiocholanolone I assay was also chosen to determine adrenocorticotropin responses in numerous other species including banded mongooses [Laver et al., 2012], African buffaloes [Ganswindt et al., 2012], Barbary macaques [Wallner et al., 1999], bushbabies [Scheun et al., 2015], and other nonhuman primates [Bahr, et al., 2000]. Based on these and our present findings, we are therefore confident that the 11-oxoaetiocholanolone I assay is valid for monitoring adrenocortical activity in golden langurs.

Various studies have demonstrated that veterinary examinations, including sedation, can cause both physiological and behavioral stress in captive and zoo-housed animals [Heistermann et al., 2006; Waiblinger et al. 2004]. Illness, injury and related treatment have also been known to elevate fGCM concentrations [Heistermann et al., 2006; Ganswindt et al., 2010; LeRoux et al., 2016]. Notably, golden 


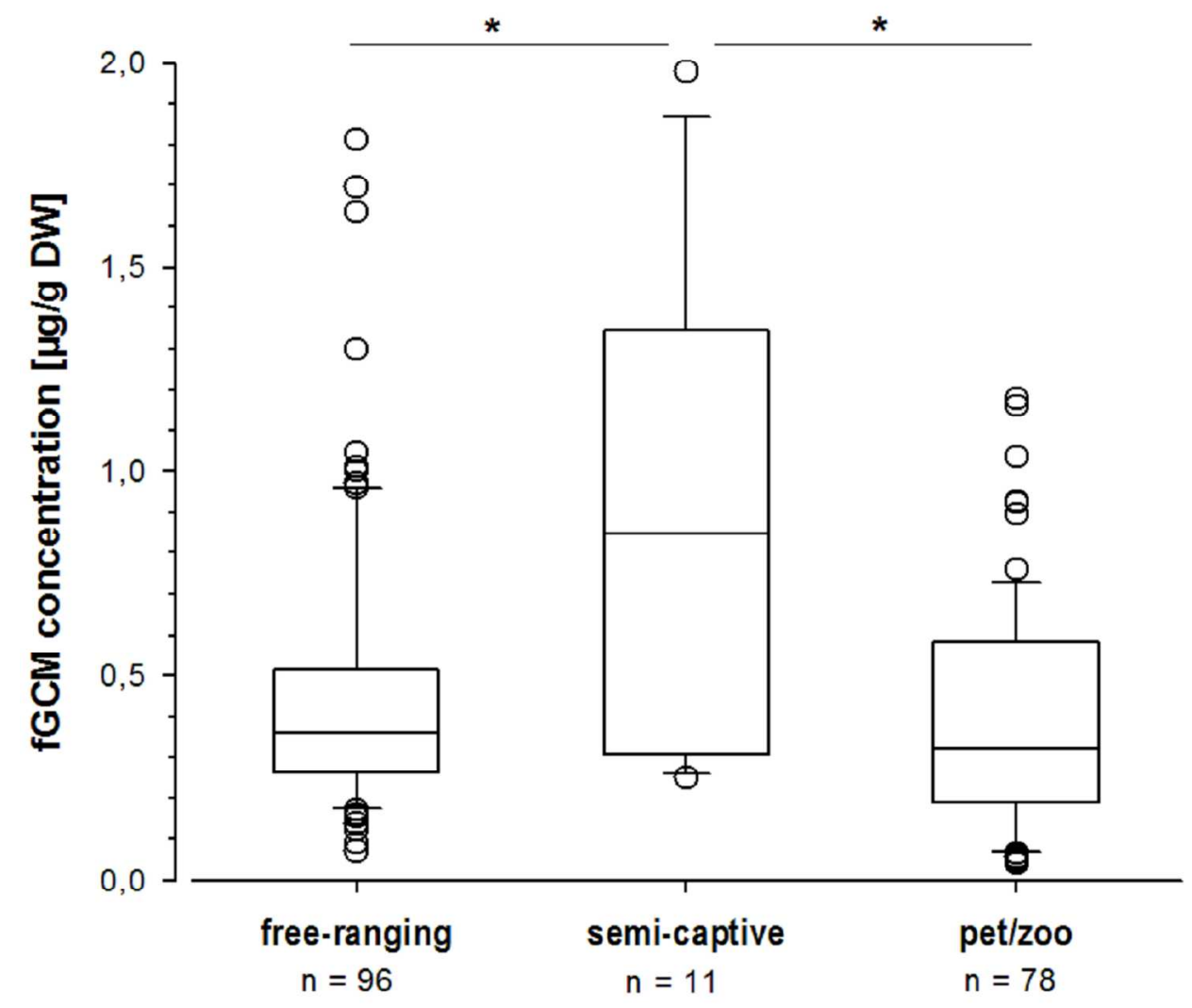

Figure 3. Box plots of immunoreactive fecal glucocorticoid metabolite (fGCM) concentrations, expressed as micrograms per gram dry weight $(\mu \mathrm{g} / \mathrm{g}$ fecal $D W)$, from golden langurs under different living conditions, $\mathrm{n}=$ number of fecal samples. Boxes indicate the median and the upper and lower quartile values, whiskers indicate 10th and 90th percentiles of the values, open circles indicate outliers. Horizontal bars and asterisks indicate significant differences between groups $(P<0.05)$.

$264 \times 228 \mathrm{~mm}(144 \times 144$ DPI) 
langur Zoo 3 had the highest concentrations of fGCM of our five individually monitored captive animals. This langur had been undergoing frequent veterinary treatment due to helminth infestation during our study period that may also affected adrenocortical activity and thus fGCM concentrations.

The three groups (wild, temple-housed, and in captivity) had different daily activities, including interactions with humans and ability to range freely. The two pet langurs roam freely during day time and find their foods in campus trees in addition to some provided by the owners. The three zoo langurs received similar food as the two pets with the exception that no processed food was provided. The CWS animals were fully free ranging and had little to no human contact. The temple island golden langurs also occupy deciduous forest but face multiple anthropogenic stressors. The temple island group is habituated to human observers and fed processed foods such as biscuits and cakes on a regular basis, a scenario somewhat comparable to urban roaming bushbabies that feed mainly on provisioned anthropogenic food sources and show elevated fGCM concentrations [Scheun et al., 2015]. For both settings, sample collection took place without identifying individuals, thus we cannot exclude the possibility of a potential sex-related bias in these sample sets by chance, which might contributed to the differences in fGCM levels found due to sex-specific steroid metabolism (Möstl et al., 2005). However, we cannot discount that similar sampling biases may have occurred in the free-ranging group. Since the golden langur is endangered and the population is in decline, the results of this study suggest future studies that are focused on the impact of human anthropogenic disturbance and food provision, particularly concerning the semi-captive population on Guwahati Island.

\section{CONCLUSIONS}

1. Fecal hormone analysis can be used to monitor adrenocortical activity in the golden langur.

2. Variations in fGCM concentration may be useful for monitoring individual golden langur health.

3. Differences in fGCM concentrations were identified from golden langurs in different living conditions, suggesting that anthropogenic activity may be a significant source of stress.

\section{ACKNOWLEDGEMENTS}

We thank the two families who have allowed us to conduct our work on ACTH challenges on their pet golden langurs. We also thank Dr. Gopal Chetry, the Research Officer of the Department of Forest, Government of Assam, Mr. Chandan Bora, Divisional Forest Officer, Government of Assam and Dr. Bhaben Kakoti, veterinarian of the Assam State Zoo cum Botanical Garden for all the permits needed to conduct this study. We thank Mr. Rajani Ranjan Hazarika for logistic support with sample storage. We 
acknowledge the help from Mr. Paramesh Talukdar and Mr. Rajen Das, the animal keepers of the Assam State Zoo cum Botanical Garden for their support and the permission and help during fecal sample collection. For their support in the laboratory, we acknowledge HC Rossouw, Swmkhwr Boro, Silistina Narzari, Kailash Barman and Hirokmoni Borgoyary for their help and assistance during sample preparation. We are indebted to Mr. Kamleswar Brahma for performing the ACTH injections in the langurs. This research was conducted with permission and in accordance with the Animal Ethical Committee of Bodoland University, Assam, India. The authors acknowledge the laboratory support in the Department of Biotechnology, Government of India sponsored Institutional Biotech Hub and Bioinformatics Infrastructure Facility at Bodoland University. This study complied with all Indian animal care regulations and applicable national laws.

\section{REFERENCES}

Bahr NI, Pryce CRP, Dobeli M, and Martin RDM. 1998. Evidence from urinary cortisol that maternal behavior is related to stress in gorillas. Physiol Behav 64:429-437.

Bahr NI, Palme R, Möhle U, Hodges JK, Heistermann M. 2000. Comparative aspects of the metabolism and excretion of cortisol in three individual nonhuman primates. Gen Comp Endocrin 117:42738.

Breazile JE. 1987. Physiological basis and consequences of distress in animals. J Am Vet Med Assoc 191:1212-1215.

Das J, Medhi R, Molur S. 2008. Trachypithecus geei. The IUCN Red List of Threatened Species 2008: e.T22037A9348940. http://dx.doi.org/10.2305/IUCN.UK.2008.RLTS.T22037A9348940.en. Downloaded on 10 August 2016.

Fichtel C, Kraus C, Ganswindt A, Heistermann M. 2007. Influence of reproductive season and rank on fecal glucocorticoid levels in free-ranging male Verreaux's sifakas (Propithecus verreauxi). Hormon Behav 51:640-648.

Ganswindt A, Heistermann M, Borragan S, Hodges JK. 2002. Assessment of testicular endocrine function in captive African elephants by measurement of urinary and fecal androgens. Zoo Biol 21:27-36.

Ganswindt A, Muenscher S, Henley M, Palme R, Thompson P, Bertschinger H. 2010. Concentrations of faecal glucocorticoid metabolites in physically injured free-ranging African elephants (Loxodonta africana). Wildl Biol 16:323-332.

Ganswindt A, Tordiffe ASW, Stam E, Howitt MJ, Jori F. 2012. Determining adrenocortical endocrine activity as a measure of stress in African buffalo (Syncerus caffer) based on faecal analysis. Afr Zool 47:261-269. 
Ganswindt SB, Myburgh JG, Cameron EZ, Ganswindt A. 2014. Non-invasive assessment of adrenocortical function in captive Nile crocodiles (Crocodilus niloticus). Comp Biochem Physiol A $177: 11-17$.

Heistermann M, Palme R, Ganswindt A. 2006. Comparison of different enzyme immunoassays for assessment of adrenocortical activity in primates based on fecal analysis. Am J Primatol 68:257273.

Horwich RH, Das R, Bose A. 2013. Conservation and the current status of the golden langur in Assam, India, with reference to Bhutan. Primat Conserv 27:77-83.

Johnson EO, Kamilaris TC, Carter CS, et al. 1996. The biobehavioral consequences of psychogenic stress in a small, social primate (Callithrix jacchus jacchus). Biol Psych 40:317-337.

Khajuria H. 1955. A new langur (primates: Colobidae) from Goalpara District, Assam. Annals Mag Nat Hist 9:86-88.

Laver P, Ganswindt A, Ganswindt SB, Williams M, Alexander K. 2012. Non-invasive monitoring of glucocorticoid metabolites in banded mongooses (Mungos mungo) in response to biological and physiological challenges. Gen Comp Endocrin 179:178-183.

LeRoux A, Botha H, Dalerum F, Ganswindt A 2016. Non-invasive measurement of adrenocortical activity in a myrmecophageous mammal, the bat-eared fox. Afr Zool http://dx.doi.org/10.1080/15627020. 2016.1145071.

Mehdi R, Chetry D, Basavdatta C, Bhattacharjee PC. 2007. Status and Diversity of Temple Primates in Northeast India. Primat Conserv 22:135-138.

Molur S, Brandon-Jones D, Dittus W, et al. 2003. Status of South Asian Primates: Conservation Assessment and Management Plan Report. Zoo Outreach Organization/CBSG-South Asia, Coimbatore, India.

Monfort SL, Mashburn KL, Brewer BA, Creel SR. 1998. Evaluating adrenal activity in African wild

dogs (Lycaon pictus) by fecal corticosteroid analysis. J Zoo Wildl Med 29:129-133.

Möstl E and Palme R. 2002. Hormones as indicators of stress. Dom Anim Endocrin 23:67-74.

Möstl, E., S. Rettenbacher \& R. Palme. 2005. Measurement of corticosterone metabolites in birds' droppings: an analytical approach. Ann New York Acad Sci 1046: 17-34.

Muehlenbein MP, Ancrenaz M, Sakong R, et al. 2012. Ape conservation physiology: fecal glucocorticoid responses in wild Pongo pygmaeus morio following human visitation. PLoS ONE 7: e33357.

Norman RL. 1993. Effects of corticotropin-releasing hormone on luteinizing hormone, testosterone, and cortisol secretion in intact male rhesus macaques. Biol Reprod 49:148-153.

Norris DO. 1996. Vertebrate Endocrinology. Academic Press, San Diego. 
Palme R, Möstl E, Brem G, Schellander K, Bamberg E. 1997. Faecal metabolites of infused 14Cprogesterone in domestic livestock. Reprod Domes Anim. 32:199-206.

Palme R, Robia C, Messmann S, Möstl E. 1998. Measuring fecal cortisol metabolites: A non-invasive tool to evaluate adrenocortical activity in mammals. Proceedings of the 2nd International Symposium on Physiology and Ethology of Wild and Zoo Animals, Berlin, Germany, 7-10 October, 1998. S. t. E. Advances in Ethology 33, p. 27.

Rimbach R, Link A, Heistermann M, et al. 2013. Effects of logging, hunting, and forest fragment size on physiological stress levels of two sympatric ateline primates in Colombia. Conserv Physiol $1: \cot 031$.

Sapolsky RM. 1987. Stress, social status and reproductive physiology in free living baboons. In Psychobiology of Reproduction: An Evolutionary Perspective. (D. Crews, Ed.). Prentice-Hall, New York.

Sapolsky RM, Share LJ. 1998. Darting terrestrial primates in the wild: A primer. Am J Primatol 44:155167.

Scheun J, Bennett N, Ganswindt A, Nowack J. 2015. The hustle of city life: Monitoring the effects of urbanization in the African lesser bushbaby, Galago moholi. Sci Nature 102:57-69.

Thompson ME. 2013. Reproductive ecology of female chimpanzees. Am J Primat 75:222-237.

Touma C, Sachser N, Möstl E., Palme R. 2003. Effects of sex and time of day on metabolism and excretion of corticosterone in urine and feces of mice. Gen Comp Endocrin 130:267-278.

Touma C, Palme R. 2005. Measuring fecal glucocorticoid metabolites in mammals and birds: the importance of validation. Annal New York Acad Sci 1046:54-74.

Waiblinger S, Menke C, Korff J, Bucher A. 2004. Previous handling and gentle interactions affect behavior and heart rate of dairy cows during a veterinary procedure. Appl Anim Behav Sci $85: 31-42$.

Wallner, B, Möstl E, Dittami J, Prossinger H. 1999. Fecal glucocorticoids document stress in female Barbary macaques (Macaca sylvanus). Gen Comp Endocrin 113:80-86.

Wangchuk T, Inouye DW, Hare MP. 2003. A new subspecies of Golden Langur (Trachypithecus geei) from Bhutan. Folia Primat 74:104-108.

Wikelski M, Cooke SJ. 2006. Conservation physiology. Trends Ecol Evol 21:38-46.

Wingfield JC, Sapolsky RM. 2003. Reproduction and resistance to stress: When and how. J Neuroendocrin 15:711-724. 